\title{
SELEÇÃO PRELIMINAR DE CLONES DE ACEROLEIRA NO ESTADO DO CEARÁ ${ }^{1}$
}

\author{
JOÃO RODRIGUES DE PAIVA ${ }^{2}$ \\ RICARDO ELESBÃO ALVES ${ }^{2}$ \\ FRANCISCO JOSÉ DE SEIXAS SANTOS ${ }^{2}$ \\ LEVI DE MOURA BARROS ${ }^{2}$ \\ ADRIANO DA SILVA ALMEIDA ${ }^{3}$ \\ CARLOS FARLEY HERBSTER MOURA ${ }^{3}$ \\ JOQUEBEDE BEZERRA CACAU ${ }^{4}$ \\ NORMÂNDIA PEREIRA NORÕES ${ }^{5}$
}

\begin{abstract}
RESUMO - O aumento da lucratividade dos pomares de aceroleira por meio da utilização de cultivares com maior produtividade e conteúdo de vitamina $\mathrm{C}$, atualmente, constitui-se no principal desafio do melhoramento genético. Com o objetivo de avaliar o desempenho de clones de aceroleira (Malpighia emarginata DC.), sob cultivo em área de produtor, foi instalado em agosto de 1999 um experimento no delineamento de blocos ao acaso com 45 clones (tratamentos), três repetições e cinco plantas por parcela. A altura de planta e o diâmetro da copa foram medidos no primeiro e segundo ano de idade. A produção de frutos foi avaliada nos meses de agosto a dezembro no ano de 2000 e de janeiro a de-
\end{abstract}

zembro em 2001. A avaliação físico-química constou da determinação do conteúdo de vitamina $\mathrm{C}$, sólidos solúveis totais ( $\left.{ }^{\circ} \mathrm{Brix}\right)$ e peso médio do fruto (PMF). Entre as principais conclusões, destacam-se: há uma tendência de a produção dos clones se estender por todos os meses do ano, exceção feita aos meses de maio e julho, que não foram favoráveis a cerca de 53\% dos clones; a seleção preliminar, considerando o desempenho satisfatório para as características morfológicas da planta e dos frutos, destaca os seguintes clones: I 13/2, I 51/1, II 26/4, III 56/4 e III 78/1; em $11 \%$ dos clones, os frutos mostram alto conteúdo de vitamina $\mathrm{C}$, acima de 1.600 $\mathrm{mg} / 100 \mathrm{~g}$ de polpa.

\section{PRELIMINARY SELECTION OF ACEROLEIRA CLONES IN CEARÁ STATE}

\begin{abstract}
The main objective to acerola breeding nowadays is to increase profitability of the orchards through the utilisation of high yield and high Vitamin $\mathrm{C}$ content cultivars. In order to evaluate the performance of acerola clones (Malpighia emarginata DC.) planted in private orchard, an experiment was set up in August 1999 arranged as randomized block design with 45 clones, 3 replicates and 5 plants per plot. Plant height and canopy diameter were measured at plant ages of one and two years. Fruit yield was evaluated from August till December in the year 2000, and from January till December in 2001. Fruit evaluation consisted of
\end{abstract}

measurements of Vitamin $\mathrm{C}$ and soluble solids ( ${ }^{\circ} \mathrm{Brix}$ ) contents and fruit average weight. Among the main conclusions it should be emphasized that: all clones tend to produce throughout the year although May and July have not been favourable to $53 \%$ of the clones; after considering satisfactory performance as for morphological plant characteristics and fruit attributes, the clones I 13/2, I 51/1, II 26/4, III56/4 and III 78/1 were chosen by preliminary selection; high Vitamin $\mathrm{C}$ content above 1600 $\mathrm{mg} / 100 \mathrm{~g}$, was found in the pulp of fruits from $11 \%$ of the clones.

INDEX TERMS: Malpighia emarginata, improvement, yields, vitamin C, selection.

1. Trabalho realizado com o suporte financeiro do Programa de Apoio ao Desenvolvimento da Agricultura Irrigada do Nordeste (PADFIN).

2. Engenheiro Agrônomo, Ph.D., Embrapa-Centro Nacional de Pesquisa de Agroindústria Tropical (CNPAT), Caixa Postal 3761, 60511-110 - Fortaleza, CE. paiva@cnpat.embrapa.br

3. Aluno de pós-graduação.

4. Aluna de graduação bolsista do PIBIC.

5. Empresa Frutacor Ltda. 


\section{INTRODUÇÃO}

O aumento da lucratividade dos pomares de aceroleira por meio da utilização de cultivares com maior produtividade e conteúdo de vitamina $\mathrm{C}$ atualmente constitui-se no principal desafio do melhoramento da espécie. Além disso, o melhoramento visa a explorar a variabilidade genética existente na obtenção de clones ou populações com maior uniformidade genética, que propiciem frutos que satisfaçam aos mais diferentes paladares, de modo a conquistar os mercados das regiões mais desenvolvidas e economicamente mais prósperas do País (PAIVA et al., 1999a).

Os procedimentos mais comuns adotados no melhoramento de plantas de reprodução assexuada ou vegetativa são a introdução de germoplasma, a seleção clonal e a hibridação, seguida de seleção. Além desses, métodos auxiliares têm sido utilizados com sucesso, como a indução de mutações, indução de poliploidia e cultura de tecidos.

A introdução de plantas no melhoramento da aceroleira (Malpighia emarginata DC.) tem sido a principal fonte de obtenção de materiais mais adequados à exploração comercial (BEZERRA et al., 1994; BOSCO et al., 1994; GONZAGA NETO e MATIUZ, 1998; PÍPOLO et al., 1998, OLIVEIRA et al., 1998). A seleção de clones é uma etapa do melhoramento de plantas de propagação vegetativa utilizada tanto após a introdução de germoplasma como da hibridação. O sucesso com essa metodologia depende da presença de indivíduos portadores de características favoráveis à seleção de clones que entrarão no processo de avaliação. Assim, o êxito do processo de seleção de clones depende da variabilidade genética existente na população base, razão pela qual a seleção feita numa população formada por um único clone, prática comum entre os produtores, não surte efeito, uma vez que toda variação existente é de origem ambiental.

A seleção de clones é a maneira mais eficiente para suprir a demanda imediata de variedades; o resultado pode ser visualizado em curto prazo e essa tem sido a principal metodologia adotada nos programas de melhoramento de aceroleira. Por ser a aceroleira uma espécie que pode ser propagada vegetativamente, o genótipo de cada planta pode ser transmitido integralmente por meio das gerações. Os genótipos multiplicados via clonagem permitem a avaliação desses em experimentos com repetições em diversos locais (ambientes) em delineamentos apropriados.

Com o presente trabalho, objetivou-se avaliar o desempenho de 45 clones de aceroleira, em relação ao desenvolvimento vegetativo das plantas, à produção e à qualidade dos frutos, sob cultivo em área de produtor.

\section{MATERIAL E MÉTODOS}

O experimento foi instalado em agosto de 1999 na Fazenda Frutacor Ltda, no município Limoeiro do Norte, CE, no delineamento de blocos ao acaso, com 45 tratamentos (clones), três repetições e cinco plantas por parcelas, no espaçamento de $5 \mathrm{~m}$ entre linhas e $4 \mathrm{~m}$ entre plantas. As parcelas estão dispostas em forma linear e a bordadura entorno do experimento foi feita com o clone I 57/4. Os tratamentos são formados por clones de acerola originados da introdução de outras regiões ou obtidos por seleção de plantas no Programa de Melhoramento Genético da Embrapa Agroindústria Tropical.

As características da área experimental são as seguintes: topografia plana, altitude de $102 \mathrm{~m}$, o solo é Cambissolo, com pH de 6,8 e a pluviosidade anual média é de $772 \mathrm{~mm}$.

O local de origem e a descrição dos clones (tratamentos) são descritos a seguir: Tomé Açú-PA (Okinawa, Camta 40.2, Barbados, Monami e Mineira); BelémPA (Flor Branca); Assú-RN: (FP 2, FP 3, FP 4, FP 5, FP 8, FP 10, FP 12, FP 15, FP 16, FP 17, FP 19, FP 20, FP 21, FP 25, FP 26 e FP 27); Petrolina-PE: (Sertaneja BR 152, utilizado como testemunha). Os clones obtidos por seleção de planta, seguido de clonagem, são os seguintes: I 6/2 (refere-se à planta número 2 da progênie 6 localizada na primeira repetição do experimento de avaliação de progênies de aceroleira), I 13/2, I 17/1, I 51/1, I 51/3, I 57/4, I 66/4, I 79/3, I 90/3, II 26/4, II 37/1, II 37/3, II 47/1, II 56/2, III 13/2, III 40/3, III 56/4, III 78/1, III $91 / 4$ e III 93/2.

Os tratos culturais foram aplicados de acordo com a recomendação para o plantio comercial da aceroleira na região. A adubação de fundação das plantas constou de 5 litros de esterco bovino, $250 \mathrm{~g}$ de superfosfato simples, $50 \mathrm{~g}$ de uréia e $30 \mathrm{~g}$ de cloreto de potássio. O suprimento de água foi feito por irrigação localizada, com microaspersores alto-compensantes com vazão de 35 litros de água/hora, sendo irrigadas, em média, três horas por dia. A fertirrigação foi feita aplicando-se mensalmente $24,0 \mathrm{~kg}$ de uréia e $13,6 \mathrm{~kg}$ de cloreto de potássio para todas as plantas, distribuindose, em média, $30 \mathrm{~g}$ de uréia e $17 \mathrm{~g}$ de $\mathrm{KCl} /$ planta.

No primeiro e segundo anos de idade das plantas, foram medidos a altura de planta (AP) e o diâmetro da copa (DCopa). A produção de frutos foi avaliada nos meses de agosto a dezembro no ano de 2000 e de janeiro a dezembro em 2001, com base em duas colheitas por semana em todo o experimento, registrando-se a 
produção total de frutos por clone/ano (PTF) e a produção média por planta/ano (PFP). No período de maio a agosto de 2001, foram colhidas amostras de frutos maduros para análise físico-química dos clones. Foram avaliados o teor de vitamina C (STROHECKER e HENNING, 1967), sólidos solúveis totais (SST) e o peso médio do fruto (PMF) no laboratório de pós-colheita da Embrapa Agroindústria Tropical.

\section{RESULTADOS E DISCUSSÃO}

Houve diferenças significativas entre clones a $1 \%$ de probabilidade, para todas os caracteres avaliados no primeiro e segundo ano (Tabela 1). Essas diferenças entre clones revelam uma condição favorável à seleção, considerando que essa variação seja de natureza genética. Os coeficientes de variação experimental mantiveram-se em níveis aceitáveis para experimentação de campo com acerola (PAIVA et al., 1999b; LOPES, 1999; CORDEIRO, 2000).

Observando-se os valores mínimos e máximos dos caracteres altura de planta e diâmetro de copa, no primeiro e no segundo ano de idade, as diferenças entre esses valores foram menores para a altura de planta em relação ao diâmetro da copa. Esse padrão de crescimento é comum aos clones que, naturalmente, apresentam conformação de copa do tipo "guarda-chuva", isto é, a copa das plantas apresentam formato que lembram esse equipamento ou de "taça invertida". Essa é uma característica vantajosa em relação à copa tipo erecto, pois facilita a colheita dos frutos, sendo, às vezes, desnecessário efetuar podas de formação.

Cordeiro (2000) avaliou por três anos o desenvolvimento de plantas originadas de progênies de acerola, mensurando as características de altura de planta e diâmetro de copa, e constatou que no terceiro ano ocorria grande freqüência de plantas que apresentavam altura igual ou inferior à do ano anterior, resultado da curvatura natural da copa daquelas plantas que apresentavam conformação do tipo "guarda-chuva".

Ainda na Tabela 1 observa-se que as médias da produção total de frutos por clone e por planta individual duplicaram os seus valores em 2001. Essas diferenças são mais evidentes quando se analisa a produção individual por clone. Isso evidencia a necessidade de avaliação dos clones por um período maior de tempo.

Os plantios comerciais no Brasil estão aquém do potencial da cultura (aproximadamente 100 $\mathrm{kg} /$ planta/ano). A maximização desse potencial para a produção e a qualidade dos frutos só será atingida quando as instituições de pesquisa (universidades, empresas de pesquisa públicas e privadas) lançarem clones de aceroleira com características desejáveis e que tenham a aceitação dos produtores para cultivá-los comercialmente (ALVES, 1997).

TABELA 1 - Quadrados médios de blocos (QMb), clones (QMc) e do resíduo (QMr) das análises de variâncias e respectivas significâncias; médias e coeficientes de variação experimental $(\mathrm{CV})$; valores mínimos e máximos para altura de planta (AP), diâmetro de copa (DCopa), produção total de frutos (PTF) e produção de frutos por planta (PFP) de 45 clones de aceroleira.

\begin{tabular}{|c|c|c|c|c|c|c|c|c|}
\hline \multirow[b]{2}{*}{ Parâmetros } & \multicolumn{4}{|c|}{2000} & \multicolumn{4}{|c|}{$\begin{array}{llll}2 & 0 & 0 & 1\end{array}$} \\
\hline & $\begin{array}{l}\mathbf{A P} \\
(\mathbf{m})\end{array}$ & $\begin{array}{c}\text { Dcopa } \\
\text { (m) }\end{array}$ & $\begin{array}{c}\mathbf{P T F}^{1} \\
(\mathbf{k g})\end{array}$ & $\begin{array}{c}\mathbf{P F P}^{1} \\
(\mathbf{k g})\end{array}$ & $\begin{array}{l}\mathbf{A P} \\
(\mathbf{m})\end{array}$ & $\begin{array}{c}\text { Dcopa } \\
\text { (m) }\end{array}$ & $\begin{array}{l}\text { PFT } \\
\text { (kg) }\end{array}$ & $\begin{array}{r}\text { PFP } \\
(\mathbf{k g})\end{array}$ \\
\hline $\mathrm{QMb}$ & 0,0092 & 0,1821 & 287,24 & 11,4828 & 0,0107 & 0,0755 & 477,29 & 19,0794 \\
\hline QMc & $0,0688 * *$ & $0,2445^{* *}$ & $382,28^{* *}$ & $15,2901 * *$ & $0,0806^{* *}$ & $0,3742 * *$ & $1908,9 * *$ & $76,3639 * *$ \\
\hline QMr & 0,0126 & 0,0430 & 47,583 & 1,9043 & 0,0151 & 0,0443 & 170,12 & 6,8046 \\
\hline Média & 1,34 & 2,19 & 30,61 & 6,12 & 1,49 & 3,23 & 63,07 & 12,61 \\
\hline $\mathrm{CV}(\%)$ & 8,37 & 9,48 & 22,54 & 22,54 & 8,25 & 6,52 & 20,68 & 20,68 \\
\hline Valor mínimo & 0,85 & 1,25 & 5,01 & 1,00 & 0,88 & 2,28 & 5,36 & 1,07 \\
\hline Valor máximo & 1,77 & 3,04 & 60,44 & 12,09 & 1,96 & 3,93 & 138,46 & 27,69 \\
\hline
\end{tabular}

${ }^{1}$ Avaliação feita no período de agosto a dezembro; ** $\mathbf{p}<0,01$. 
Na Figura 1 encontra-se a distribuição da produção de frutos dos clones por mês no período de agosto de 2000 a dezembro de 2001, verificando-se que a produção total mensal de frutos variou de $29,8 \mathrm{~kg}$ a 25.558 $\mathrm{kg}$ nos meses de julho e dezembro de 2001, respectivamente. A ocorrência de produção em todos os meses, apesar da redução nos meses de maio e julho, significa que entre os 45 clones existem alguns que não interromperam a produção de frutos ao longo do período de avaliação. A quantidade de clones e o período em que deixaram de produzir foram os seguintes: no ano de 2000 - um clone em agosto; no ano de 2001 - cinco clones em fevereiro, três clones em março, 12 clones em maio, 14 clones em julho e cinco clones em agosto. Considera-se que a produção contínua de frutos é favo- rável ao pequeno produtor por fornecer renda ao longo do ano. Entretanto, dificulta a alocação de mão-de-obra para o grande produtor. Nesse caso, os clones com produção concentrada em alguns meses do ano devem ser os preferidos.

Para caracterizar melhor o desempenho dos clones em relação ao conteúdo de vitamina $\mathrm{C}$, foi feita uma classificação em cinco grupos: a) conteúdo de vitamina $\mathrm{C}$ abaixo de $0,7 \%$; b) conteúdo de vitamina $\mathrm{C}$ de $0,7 \%$ a $1 \%$; c) conteúdo de vitamina $\mathrm{C}$ de $1 \%-1,3 \%$; $)$ conteúdo de vitamina $\mathrm{C}$ de $1,3 \%$ a $1,6 \%$; e e) conteúdo de vitamina $\mathrm{C}$ acima de $1,6 \%$ (Figura 2). A maioria dos clones, cerca de $67 \%$, foi enquadrada nos grupos "c" e "d". O grupo "e", com maior conteúdo de vitamina C, contemplou $11 \%$ dos clones.

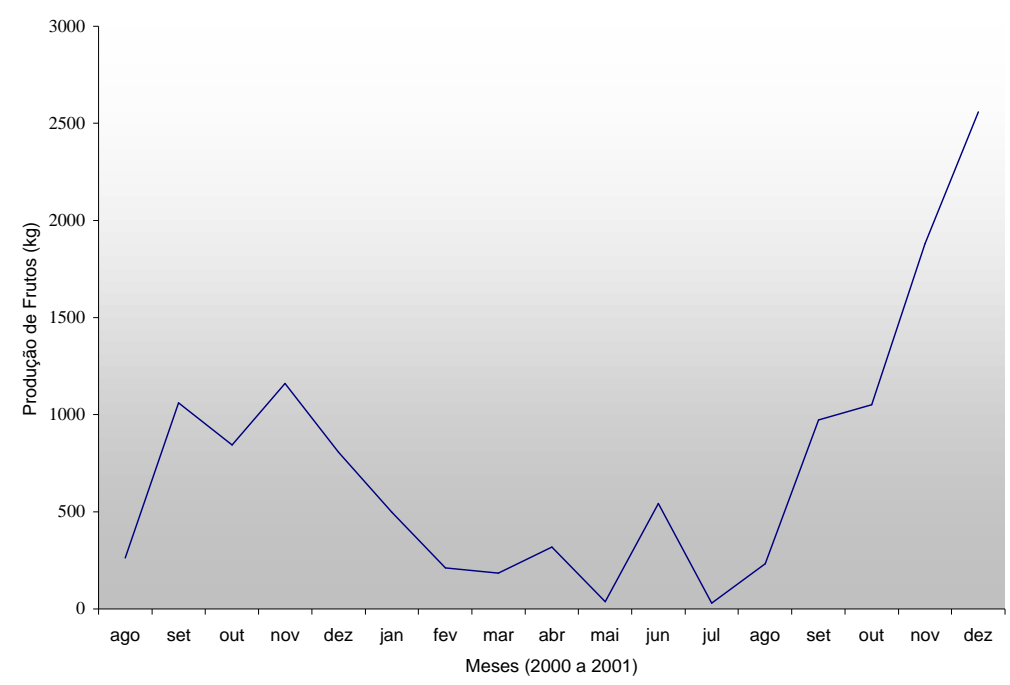

FIGURA 1 - Produção mensal de frutos de 45 clones de acerola no município de Limoeiro do Norte, CE, no período de agosto de 2000 a dezembro de 2001.

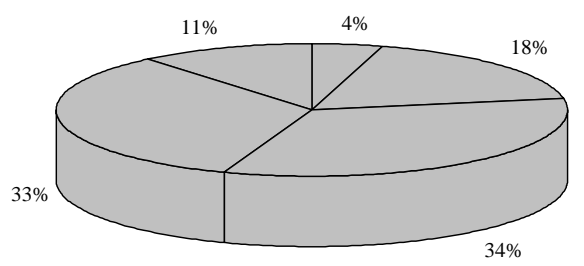

$\square<0,7 \% \square 0,7-1 \% \square 1-1,3 \% \mathbf{\square} 1,3-1,6 \% \mathbf{\square}>1,6 \%$

FIGURA 2 - Porcentagem de clones de aceroleira em função do conteúdo de vitamina dos frutos avaliados no município de Limoeiro do Norte, CE, no período de janeiro a dezembro de 2001. 
A seleção de plantas de aceroleira em pomares comerciais é feita, principalmente, com base nas características da planta (porte e tipo de copa) e do fruto (tamanho, sabor, consistência e coloração) (BOSCO et al., 1994; BEZERRA et al., 1994). Provavelmente, isso ocorre em razão do grande número de plantas avaliadas e da dificuldade de efetuarem-se avaliações de outras características em plantios de particulares.

Quando se avaliam clones, em que o número de plantas é menor que no plantio comercial, geralmente, conduzidos em estações experimentais, são consideradas ainda as seguintes características: peso, tamanho e número de frutos, teor de sólidos solúveis, acidez titulável, $\mathrm{pH}$, teor de ácido ascórbico, fenologia da planta, além dos caracteres morfológicos (YAMANE e NAKASONE, 1961; NAKASONE et al., 1968; GONZAGA NETO e SOARES, 1994; BEZERRA et al., 1994; ALVES e MENEZES, 1994).

Com base no desempenho satisfatório, verificado até o momento, para as características morfológicas da planta e dos frutos, foram selecionados os seguintes clones: I 13/2, I 51/1, II 26/4, III 56/4 e III 78/1. Na Figura 3 são destacadas as produções totais anuais desses clones, comparados à testemunha (Sertaneja BR 152). A menor produção foi verificada para o clone II 26/4 e a maior para o I 13/2, respectivamente com $202,02 \mathrm{~kg}$ e $340,69 \mathrm{~kg}$ de frutos para o ano de 2001. Esse último valor foi superior à testemunha em cerca de $48 \%$. As pro- duções de frutos por planta no ano de 2001 foram de $13,47 \mathrm{~kg}, 15,09 \mathrm{~kg}, 20,78 \mathrm{~kg}, 21,51 \mathrm{~kg}$ e $22,71 \mathrm{~kg}$, respectivamente para os clones II 26/4, I 51/1, III 78/1, III $56 / 4$ e I 13/2, ao passo que a testemunha (Sertaneja BR 152) produziu $15,36 \mathrm{~kg}$.

Na Figura 4 são apresentados os dados do teor de vitamina $\mathrm{C}$, peso médio de frutos e teor de sólidos solúveis totais dos clones selecionados, comparados à testemunha (clone Sertaneja BR 152). O conteúdo de vitamina $\mathrm{C}$ dos clones II 26/4 e I 51/1 foram superiores à testemunha, com $1,7 \%$ e $1,8 \%$, respectivamente, ao passo que o teor de sólidos solúveis totais ( ${ }^{\mathrm{b}}$ brix) foi superior em todos os clones, com exceção do I 51/1, que mediu somente 6,2 . O peso médio de frutos foi maior para os clones III 78/1, I 51/1 e I 13/2, com 9,1 g, 7,6 g e $11,7 \mathrm{~g}$, respectivamente.

Como é indicado na fruticultura moderna, devese buscar a maior produtividade possível dentro de cada exploração comercial, visando à minimização dos custos e à maximização da competitividade. Entretanto, é preciso que a produção seja compensadora e a qualidade dos frutos, uniforme. Esses padrões serão alcançados com o uso de clones, pois com o plantio desse material, haverá pomares com menor variação na produtividade e na qualidade do fruto (acidez, açúcares e teor de vitamina C), facilitando a padronização, diferentemente do que ocorre com material atualmente em uso, que é originado de sementes.

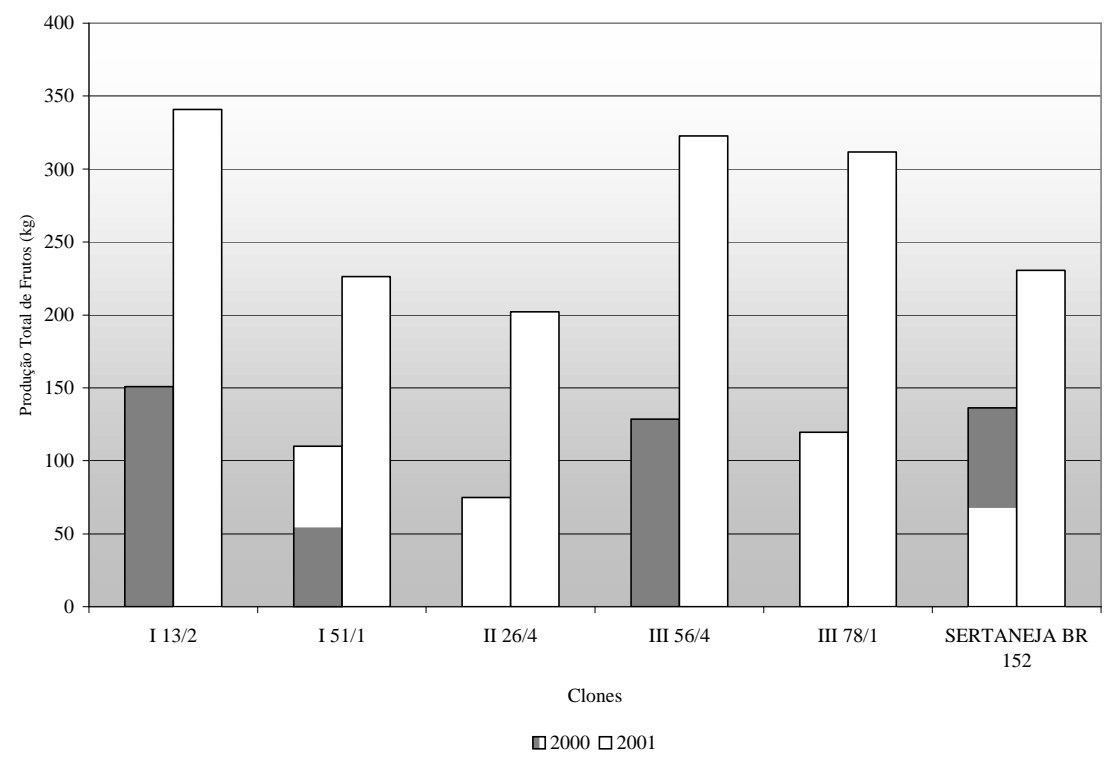

FIGURA 3 - Produção mensal de frutos de seis clones de acerola no município de Limoeiro do Norte, CE, no período de agosto de 2000 a dezembro de 2001.

Ciênc. agrotec., Lavras. V.27, n.5, p.1038-1044, set./out., 2003 


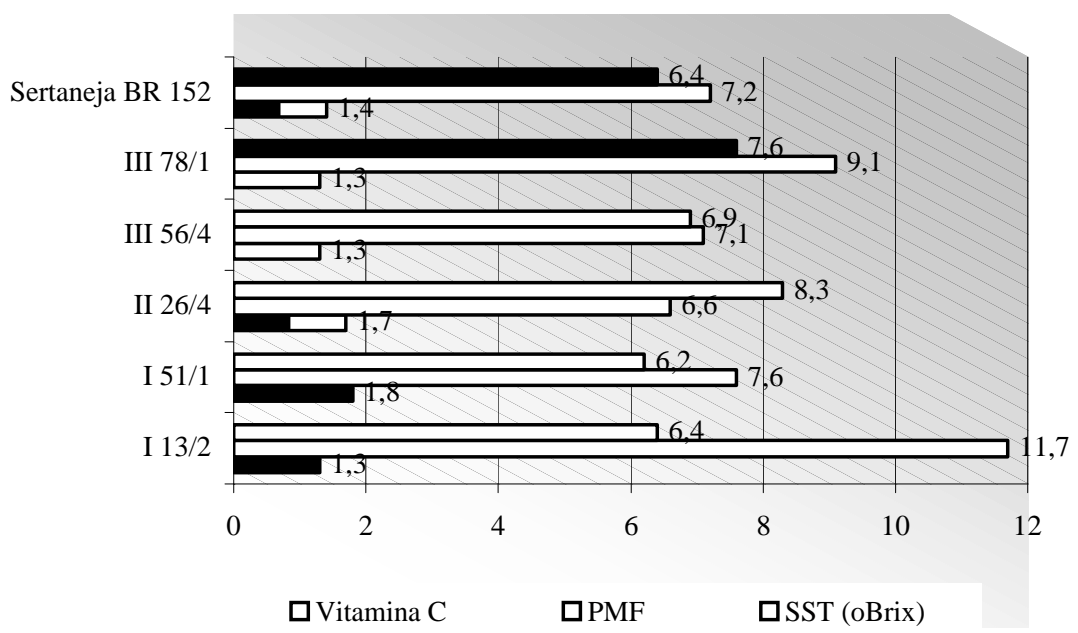

FIGURA 4 - Porcentagem de vitamina C (\%), peso médio de frutos (PMF - g) e sólidos solúveis totais (SST - brix) de seis clones de aceroleira avaliados no município de Limoeiro do Norte, CE.

\section{CONCLUSÕES}

a) Há tendência de a produção de frutos dos clones se estender por todos os meses do ano, exceção feita aos meses de maio e julho;

b) A seleção preliminar de clones com desempenho satisfatório para as características morfológicas da planta e dos frutos destaca os seguintes: I 13/2, I 51/1, II 26/4, III 56/4 e III 78/1;

c) Onze por cento dos clones produziram frutos com teores de vitamina $\mathrm{C}$ superiores a 1,6\%.

\section{AGRADECIMENTOS}

Ao Programa de Apoio e Desenvolvimento da Fruticultura Irrigada no Nordeste - PADFIN, pelo suporte financeiro, e à Empresa FRUTACOR Ltda, por permitir a instalação do experimento em sua propriedade.

\section{REFERÊNCIAS BIBLIOGRÁFICAS}

ALVES, R. E. Melhoramento da aceroleira. In: SIMPÓSIO BRASILEIRO DE MELHORAMENTO DE FRUTEIRAS, 1., 1997, Jaboticabal. Anais... Jaboticabal: FCAVJ/UNESP, 1997. p. 117.

ALVES, R. E.; MENEZES, J. B. Caracterização póscolheita de acerolas vermelhas e amarelas colhidas em pomar comercial. In: CONGRESSO BRASILEIRO DE FRUTICULTURA, 13., 1994, Salvador. Anais... Salvador: SBF, 1994. p. 99.
BEZERRA, J. E. F.; LEDERMAN, I. E.; CARVALHO, P. S.; MELO NETO, M. L. Avaliação de clones de aceroleira no região do vale do rio moxotó-PE: I-plantas juvenis. In: CONGRESSO BRASILEIRO DE FRUTICULTURA, 13., 1994, Salvador. Anais... Salvador: SBF, 1994. p. 85-86.

BOSCO, J.; AGUIAR FILHO, S. P.; BARREIRO NETO, M. Características fenológicas de plantas de aceroleira. In: CONGRESSO BRASILEIRO DE FRUTICULTURA, 13., 1994, Salvador. Anais... Salvador: SBF, 1994. p. 87-88.

CORDEIRO, E. R. Seleção de progênies de polinização livre de acerola e estimativas de parâmetros genéticos. 2000. 64 f. Dissertação (Mestrado em Fitotecnia) - Centro de Ciências Agrárias, Universidade Federal do Ceará, Fortaleza, 2000.

GONZAGA NETO, L.; SOARES, J. M. Acerola para exportação: aspectos técnicos de produção. Brasília: MAARA/SDR/FRUPEX/EMBRAPA-SPI, 1994. 43 p. (FRUPEX. Publicações Técnicas, 10).

GONZAGA NETO, L.; MATIUZ, B. Competição de clones de aceroleira na região do submédio São Francisco. In: CONGRESSO BRASILEIRO DE FRUTICULTURA, 15, 1998, Poços de Caldas. Anais... Lavras: UFLA, 1998. p. 53.

LOPES, R. Polimorfismo, sistema de acasalamento, polinizações, repetibilidade de características do fru- 
to e avaliação de genótipos de aceroleira (Malpighia emarginata DC.). 1999. 146 f. Dissertação (Mestrado) Universidade Federal de Viçosa, Viçosa, 1999.

NAKASONE, H. Y.; YAMANE, G. M.; MIYASHITA, R. K. Selection, evaluation, and naming of acerola ( $M$. glabra L.) cultivars. Hawaii: University of Hawaii, 1968. 19 p. Circular n. 65.

OLIVEIRA, J. R. P.; SOARES FILHO, W. S.; NASCIMENTO, A. S.; COSTA, D. C.; MATSUURA, F. C. A. U.; GOMES, J. C.; CARVALHO, J. E. B.; REINAHRDT, D. H.; OLIVEIRA, R. P. Programa de pesquisa de acerola: Embrapa Mandioca e Fruticultura. Cruz das Almas: EMBRAPA-CNPMF, 1998. 28 p. (EMBRAPA-CNPMF. Documentos, 75).

PAIVA, J. R.; ALVES, R. E.; BARROS, L. M. Melhoramento genético da acerola (Malpighia emarginata D.C.) na Embrapa Agroindústria Tropical. In: QUEIRÓZ, M. A. de; GOEDERT, C. O.; RAMOS, S. R. R. (Eds.). Recursos genéticos e melhoramento de plantas para o Nordeste brasileiro. Petrolina: Embrapa Semi-Árido; Brasília: Embrapa Recursos Genéticos e
Biotecnologia, 1999a. Disponível em: <http: llwww. cpatsa.embrapa.br>. Acesso em: 03 jun. 2002.

PAIVA, J. R.; ALVES, R. E.; CORREA, M. P. F.; FREIRE, F. C. O.; BRAGA SOBRINHO, R.; JUCÁ, W. Seleção massal de acerola (Malpighia spp.) em plantio comercial. Pesquisa Agropecuária Brasileira, Brasília, v. 34, n. 3, p. 505-511, 1999b.

PÍPOLO, V. C.; PRETE, C. E. C.; GONZALEZ, M. G. N.; POPPER, I. O.; BRUEL, D. C.; DIAS, A. M. Novos cultivares de acerola: UEL-3 Dominga, UEL-4 Ligia, UEL-5 Natália. In: CONGRESSO BRASILEIRO DE FRUTICULTURA, 15., 1998, Poços de Caldas. Anais... Lavras: UFLA, 1998. p. 52.

STROHECKER, R.; HENNING, H. M. Analisis de vitaminas: metodos comprobados. Madrid: Paz Montalvo, $1967.428 \mathrm{p}$.

YAMANE, G. M.; NAKASONE, H. Y. Pollination and fruit set studies of Acerola (Malpighia glabra L.) in Hawaii. Proceedings of the American Society for Horticultural Science, Beltsville, v. 78, p. 141-148, 1961. 